\title{
MUITO A SER DITO EM POUCAS LINHAS
}

\author{
Apresentação ao número especial da Revista da Faculdade de Direito da USP \\ comemorativo dos cinquenta anos da organização da Pós-Graduação \\ no Brasil e de seu Programa de Pós-Graduação
}

Fernando Facury Scaff ${ }^{1}$ e Ana Elisa Liberatore S. Bechara ${ }^{2}$

\begin{abstract}
Cara leitora e leitor,
1. Quis a fortuna que estivéssemos à frente da Presidência do Programa de PósGraduação em Direito da USP por ocasião da efeméride dos cinquenta anos de sua implantação, o que coincide com a organização dos cursos de pós-graduação no Brasil, realizada por meio do Parecer do Conselho Federal de Educação 977/65, conhecido na área educacional pelo nome de seu subscritor, Newton Sucupira.

Daí surgiu a ideia de organizar uma coletânea de artigos em comemoração a estes dois eventos. Inicialmente pensou-se em veicular estes textos em um livro coletivo, como tantos outros publicados e que têm vida e circulação restrita, porém a opção foi pela veiculação por meio de número especial e temático desta centenária Revista, para deixá-lo como um marco indelével na história da Faculdade de Direito da USP, e com acesso livre e imediato ao seu conteúdo, cujo acervo encontra-se disponibilizado na rede mundial de computadores.
\end{abstract}

Em face da proximidade com outra efeméride, os cem anos da Semana de Arte Moderna de 1922, optou-se por ilustrar a capa com a tela Estrada de Ferro Central do Brasil, de Tarsila do Amaral, que faz parte da coleção do Museu de Arte Contemporânea da Universidade de São Paulo, dirigido por Ana Gonçalves Magalhães, e que foi gentilmente cedida pela família da artista, sem ônus.

2. Os textos foram organizados em grupos.

Inicialmente, encontra-se esta Apresentação e o Prefácio desta obra, que honrosamente foi elaborado pela Profa. Claudia Mansani Queda de Toledo, atual Presidente da Capes, primeira mulher da área jurídica a exercer tão honroso cargo e a quem agradecemos a gentileza do texto.

$\mathrm{Na}$ sequência, encontram-se reflexões dos atuais Vice-Reitor, Professor Antonio Carlos Hernandes e do Pró-Reitor de Pós-Graduação da USP, Professor Carlos Gilberto Carlotti Junior, abordando aspectos gerais dos estudos pós-graduados no país e nesta Universidade.

\footnotetext{
1 Professor Titular de Direito Financeiro da Faculdade de Direito da Universidade de São Paulo, atualmente no exercício da Presidência da Comissão de Pós-Graduação da Faculdade (2018-2022).

2 Professora Titular de Direito Penal da Faculdade de Direito da Universidade de São Paulo, atualmente no exercício da Vice-Presidência da Comissão de Pós-Graduação da Faculdade (2018-2022).
} 
Posteriormente foram agrupados textos referentes aos cinquenta anos do nosso Programa de Pós-Graduação da Faculdade de Direito da USP e, na sequência, os artigos que se relacionam aos cinquenta anos da Pós-Graduação em Direito no Brasil.

A publicação encerra-se com o registro histórico do discurso de despedida da Presidência da Comissão de Pós-Graduação da Faculdade de Direito da USP realizado pelo Professor Goffredo da Silva Telles Junior, aos 10 de dezembro de 1973. Autor da Carta aos Brasileiros, o saudoso Professor Emérito das Arcadas foi o responsável pela elaboração do primeiro texto normativo a disciplinar o Programa de Pós-Graduação em Direito da USP, além de haver exercido a coordenação do Programa no período de sua implementação, consolidando-o. Seu discurso representa assim, o testemunho dos inúmeros desafios - todos superados com êxito - da construção de um Programa de Pós-Graduação em Direito voltado à reflexão crítica e, assim, à contribuição para o desenvolvimento científico brasileiro. O registro das palavras do Prof. Goffredo da Silva Telles Júnior representa, portanto, uma justa homenagem a esse protagonista da história da Pós-Graduação em Direito no Brasil.

Agradecemos a todos os autores e autoras que atenderam ao nosso convite, com a maestria de suas penas, o que muito nos honrou e enriqueceu esta comemoração. Recomendamos a leitura integral da obra, que diz muito sobre o passado, presente e futuro sobre o ensino e pesquisa em Direito e seu papel no desenvolvimento institucional e social de nosso país.

3. Estes cinquenta anos (1971-2021), no âmbito nacional, foram caracterizados por muitas mudanças políticas no Brasil, que saiu de um regime militar, autoritário, para uma redemocratização, com amplas liberdades, embora permaneça a grande desigualdade social, triste marca que o caracteriza.

Essa trajetória, no âmbito educacional jurídico, pode ser constatada pela composição dos diversos curricula dos Programas de Pós-Graduação em Direito, cujas disciplinas refletem tais modificações. Apenas um exemplo comprova este fato: antes, no âmbito do Direito Constitucional analisavam-se questões referentes à hierarquia normativa dos Atos Institucionais frente à Constituição de 1967, e se a Emenda 01/69 se caracterizava ou não como uma nova Constituição; hoje, felizmente, tais debates se inserem como matéria estudada pela disciplina História do Direito - espera-se que assim permaneça.

Por outro lado, no que se refere ao Programa de Pós-Graduação em Direito da USP, constata-se que esse período também acarretou muitas mudanças, como não poderia deixar de ser. De curricula que se caracterizavam como uma continuação dos estudos de graduação, até mesmo pelo nome das disciplinas, passou-se a ter maior atualidade e interdisciplinaridade na oferta de conteúdos. Temas relacionados à bioética, gênero, ações afirmativas, direito e arte, regulação econômica, dentre vários outros, são 
ofertados a cada semestre letivo aos discentes do Programa. A dinâmica social mudou e, com ela, a oferta de saberes por parte do corpo docente do Programa.

Desnecessário fazer, nesta Apresentação, um detalhado panorama desse período. Os textos ora publicados falam por si e demonstram esta trajetória.

4. No âmbito do Programa de Pós-Graduação em Direito da USP, tais mudanças também ocorreram. Tivemos a honra de suceder na Presidência diversos qualificados professores, como Goffredo da Silva Telles Júnior, Vicente Marotta Rangel, José Eduardo Faria, Ada Pellegrini Grinover, Otávio Bueno Magano, Eros Grau, Ignácio Poveda Velasco, José Rogério Cruz e Tucci, Antonio Luís Chaves Camargo, Monica Herman Caggiano, Fernando Dias Menezes de Almeida, José Fernando Simão, dentre muitos outros, que, cada qual a seu tempo e modo, imprimiram uma dinâmica própria à Área.

Nos dois últimos anos, premidos pela pandemia de covid-19 que grassa em nosso país, foi necessário migrar para as telas dos computadores, interconectados pela internet, todas as atividades de administrativas, e também as de ensino, pesquisa e extensão, necessárias ao desenvolvimento dos trabalhos. Apenas um exemplo: durante esse período foram regularmente realizadas seleções de ingresso ao Programa, em conjunto com a FUVEST, todas coordenadas pelo Professor Gustavo Ferraz de Campos Mônaco, sendo as duas últimas realizadas integralmente on-line, de forma inédita, com quase quatro mil candidatos.

A despeito da pandemia ter influenciado de modo determinante as mudanças de gestão nos dois últimos anos de nosso mandato, muito foi realizado nesse período, espelhando a trajetória histórica relatada: (1) foi realizado na Faculdade de Direito da USP o $2^{\circ}$ Fórum de Coordenadores de Programas de Pós-Graduação em Direito do Brasil; (2) foram aprovados novos Regimento e Regulamento para o Programa; (3) foram estabelecidas regras mais rígidas para credenciamento e recredenciamento de docentes na Pós-Graduação da Faculdade; (4) houve a reestruturação das linhas e projetos de pesquisa; (5) também ocorreu o aumento da oferta de disciplinas em língua estrangeira e com docentes estrangeiros; (6) ampliou-se a interdisciplinaridade na oferta de disciplinas; (7) foi criado um Programa de Ações Afirmativas para o ingresso e a permanência de grupos vulneráveis, bem como o levantamento de dados sobre (a) os candidatos e candidatas que buscam cursar pós-graduação na Faculdade de Direito da USP, (b) nosso atual corpo discente e (c) nosso corpo docente, para identificar seu perfil de gênero, socioeconômico e de vulnerabilidade; (8) ocorreu a mudança de ingresso para semestral (uma seleção, duas entradas); (9) foi alterada a nomenclatura dos títulos concedidos, para mestre e doutor em Direito, e não mais em Ciências; (10) foi iniciado o Programa de intercâmbio interno para discentes de outras Universidades brasileiras; (11) o número de bolsas praticamente duplicou, embora permaneça infinitamente 
inferior à demanda; (12) conseguimos, por meio de esforço coletivo do corpo docente, reverter o conceito inicialmente atribuído ao Programa na avaliação quadrienal de 20132016, retornando ao conceito 6, na Capes; (13) foram apoiados incontáveis eventos internacionais, com a participação de docentes estrangeiros no Programa, bem como de nossos docentes em eventos no exterior; (14) foi criado um Programa de incentivo à publicação em qualificados periódicos estrangeiros pelos docentes; (15) houve incremento da atuação conjunta com a Comissão de Graduação, não só para a realização das Semanas Pedagógicas, bem como para o PAE - Programa de Aperfeiçoamento do Ensino; (16) em conjunto com a Comissão de Pesquisa foi realizado o $1^{\circ}$ Seminário dos Doutores em Direito pela USP, com apresentação de trabalhos de nossos egressos; (17) foi incrementada a Biblioteca digital de teses e dissertações; (18) ocorreu o início de parcerias com a África portuguesa, por meio da realização conjunta de eventos, oferta de disciplinas e participação em bancas de doutorado; (19) foi implantado novo site do Programa, bilíngue, e com detalhamento das diferentes áreas de concentração, linhas, projetos e disciplinas ministradas pelos docentes credenciados no Programa; (20) foi finalizado o Programa Minter - Mestrado Interinstitucional realizado em conjunto com o Ciesa/Manaus; e (21) foi formalizado novo Programa Minter a ser desenvolvido em conjunto com a ESMPU- Escola Superior do Ministério Público da União; dentre muitas outras atividades.

Tudo isso viabilizou melhor formação para os 1.722 mestres e 969 doutores titulados nesse quadriênio.

5. Nada disso teria sido possível sem a confiança e o apoio de diversas pessoas, que foram decisivas para a consecução das iniciativas mencionadas, a quem agradecemos.

Correndo o risco de omissão, fazemos questão de registrar agradecimentos específicos.

Foi decisivo o incentivo da Direção da Faculdade de Direito, composta pelo Diretor, Professor Floriano de Azevedo Marques Neto, e pelo Vice-Diretor, Professor Celso Campilongo, a todas as iniciativas que apresentamos. Apoio sempre incondicional e irrestrito às propostas apresentadas, seja no âmbito de suas atividades, seja capitaneando a Congregação da Faculdade.

Uma palavra especial deve ser dedicada ao Pró-Reitor de Pós-Graduação, Professor Carlos Carlotti Júnior. Sua liderança permitiu que as mudanças apresentadas fossem aprovadas, por mais ousadas que parecessem ser.

Outro agradecimento deve ser dedicado a dois grupos de docentes: a todos os 214 professores atualmente credenciados no Programa da Pós-Graduação em Direito da USP, e a todos os colegas que, ao longo desses mandatos, compuseram o Colegiado do Programa. Sem eles, os resultados obtidos não teriam sido alcançados. Uma palavra especial de agradecimento deve ser dada ao Professor Otávio Luiz Rodrigues Jr., que 
compõe o Colegiado da Pós-Graduação da Faculdade de Direito da USP e também exerce a função de Coordenador da Área de Direito na Capes, sempre servindo de norte para a presente gestão.

Finalmente, mas não menos importante, registramos dois outros grupos que contribuíram para esses resultados: os servidores, tanto os vinculados à Comissão de Pós-Graduação, quanto aos da Faculdade de Direito, e sem esquecer a briosa equipe da Pró-Reitoria de Pós-Graduação - sem seu apoio, nada teria sido possível; e as todos os representantes discentes, sempre atentos e participativos com referência às propostas formuladas.

6. Enfim, passados cinquenta anos, qual o papel da pós-graduação em Direito em nosso país?

Oswald de Andrade, ex-aluno das Arcadas e um dos líderes da Semana de Arte Moderna de 1922, escreveu no Manifesto Antropófago, sobre a coragem de pensar, afastando teorias colonizadoras que pouco diziam a respeito da realidade brasileira:

Contra todos os importadores de consciência enlatada. A existência palpável da vida. (...) Contra o mundo reversivel e as idéas objectivadas. Cadaverizadas. $\mathrm{O}$ stop do pensamento que é dynamico. $\mathrm{O}$ indivíduo victima do systema. Fonte das injustiças clássicas. Das injustiças românticas. E o esquecimento das conquistas interiores.

Eis o legado desses cinquenta anos de estudos pós-graduados em Direito, na Faculdade de Direito da USP e em todo o Brasil: produção teórica própria, sem importações cruas ou com eventuais adaptações inadequadas. É necessário digerir o que se lê, e produzir cultura jurídica brasileira, autóctone, em busca da solução de nossos problemas. Isso foi feito ao longo desses primeiros cinquenta anos; deve permanecer e ser ampliado, sob a condução de outros colegas.

Com Carl Gustav Jung aprendemos que "cada qual carrega a tocha do conhecimento por um certo trecho do percurso, só até entregá-la a outro" . É o que fazemos, de modo republicano - passando a batuta desta afinada orquestra aos que nos sucederão, convictos de termos regido uma ária, pequena parte de todo o concerto que prossegue.

Boa jornada aos que virão!

Arcadas, junho de 2021. 